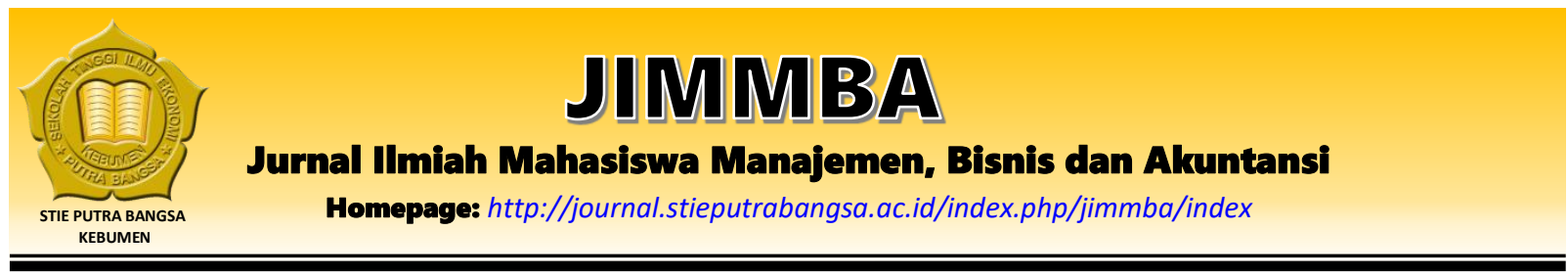

\title{
Pengaruh Sales Promotion, Hedonic Shopping Motivation dan Shopping Lifestyle Terhadap Impulse Buying pada E-Commerce Shopee
}

\author{
Reni Suci Wahyuni' ${ }^{1}$ Harini Abrilia Setyawati ${ }^{2}$ \\ 1STIE Putra Bangsa \\ 2STIE Putra Bangsa \\ Email: renisuciwahyuni97@gmail.com
}

\section{ARTICLE INFO}

Article History:

Received: March 2nd 2020

Accepted: March 5th 2020

Published: April 30th 2020

Keywords:

Sales Promotion, Hedonic

Shopping Motivation,

Shopping Lifestyle

\begin{abstract}
Tujuan penelitian ini adalah untuk mengetahui pengaruh Sales Promotion, Hedonic Shopping Motivation dan Shopping Lifestyle terhadap Impulse Buying pada e-commerce Shopee sehingga nantinya dapat menjadi referensi dalam dunia e-commerce. Penelitian dilakukan di Kebumen dengan sampel sebanyak 100 responden. Variabel yang digunakan dalam penelitian ini meliputi Sales Promotion, Hedonic Shopping Motivation dan Shopping Lifestyle sebagai variabel independen atau variabel bebas dan Impulse Buying sebagai variabel dependen atau variabel terikat. Data yang digunakan dalam penelitian ini adalah data primer, diperoleh dari hasil jawaban responden yang dikumpulkan dengan bantuan kuisioner. Metode pengambilan sampel menggunakan dengan Tehnik non probability sampling yang digunakan dalam penelitian ini yaitu dengan tehnik purposive sampling yaitu teknik untuk menentukan sampel dengan pertimbangan tertentu. Metode analisis yang digunakan dalam penelitian ini adalah uji validitas, uji reliabilitas, tahap analisa menggunakan Regresi Linear Berganda dan pengujian hipotesis. Dengan bantuan program SPSS 25 for windows. Hasil penelitian ini menunjukkan bahwa variabel Sales promotion, Hedonic Shopping Motivation dan Shopping Lifestyle mempunyai pengaruh yang signifikan terhadap Impulse Buying pada e-commerce Shopee baik secara parsial atau simultan.
\end{abstract}

\section{Pendahuluan}

Majunya teknologi dan arus informasi membuat masyarakat Indonesia lebih terbuka pada pengetahuan global. Pesatnya jaringan internet juga secara tidak langsung membawa fenomena baru atau gaya hidup baru dikalangan masyarakat yang suka memanfaatkan fasilitas internet. Pemanfaatan Teknologi Informasi dan Komunikasi (TIK) semakin berkembang bukan hanya memberikan layanan dan kemudahan mendpat informasi, namun juga dimanfaatkan sebagai media komunikasi pemasaran berbasis digital. Pertumbuhan $e-$ commerce yang semakin meningkat dari tahun ke tahun terlihat dari nilai investasi dibidang $e-$ commerce yang mencapai lebih dari USD 5 Miliar pada tahun 2017 (Nextren, 2018). 
Pemanfaatan teknologi internet dalam industri perdagangan telah mengubah perilaku pembelian konsumen. Perilaku pembelanjaan online masyarakat semakin meningkat dari tahun ke tahun. Berdasarkan hasil penelitian tahunan yang dikeluarkan We Are Social menunjukkan, persentase masyarakat Indonesia yang membeli barang dan jasa secara online dalam kurun waktu sebulan di 2017 mencapai 41\% dari total populasi, meningkat 15\% dibanding tahun 2016 yang hanya 26\% (Nextren, 2018).

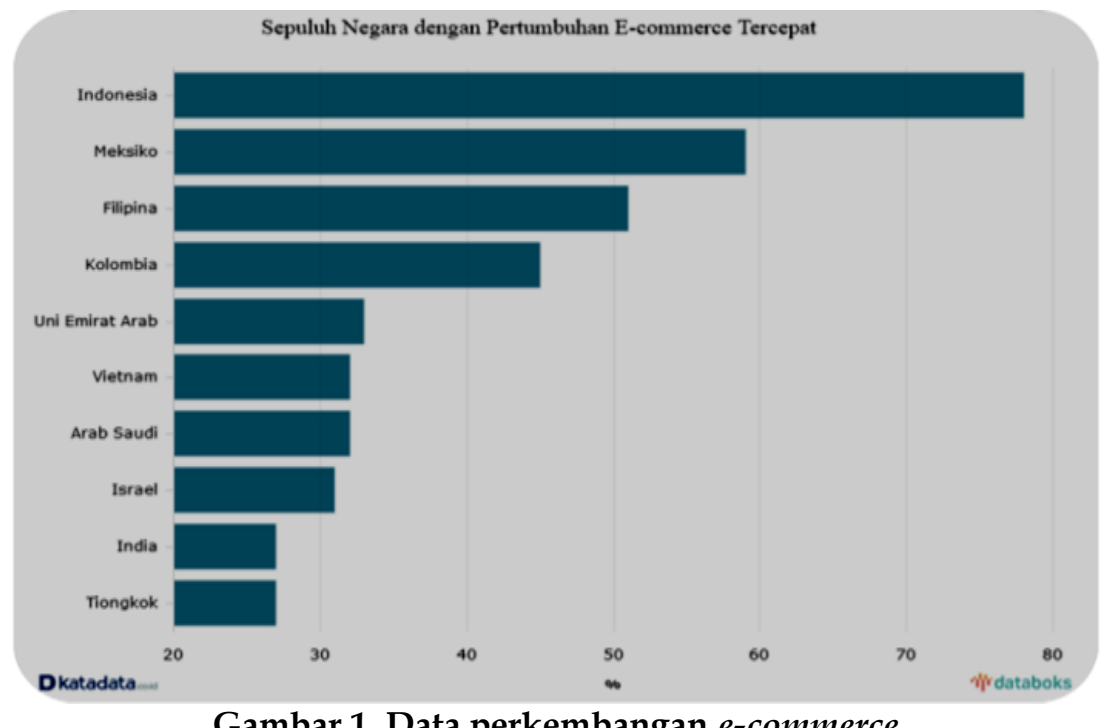

Sumber: Databoks,2019

Shopee adalah salah satu situs online yang berhasil menjadi pemain baru di industri ini masih memiliki kesempatan untuk mencadi pemain e-commerce terbaik di Indonesia. Shopee yang selama 2 tahun belakangan naik turun di posisi 3,4 dan 5. Pada kuartal pertama tahun 2019 Shopee masih diurutan ke 3 setelah Tokopedia dan Bukalapak.

Tabel 1. Data pengunjung e-commerce pada kuartal ke 1 tahun 2019

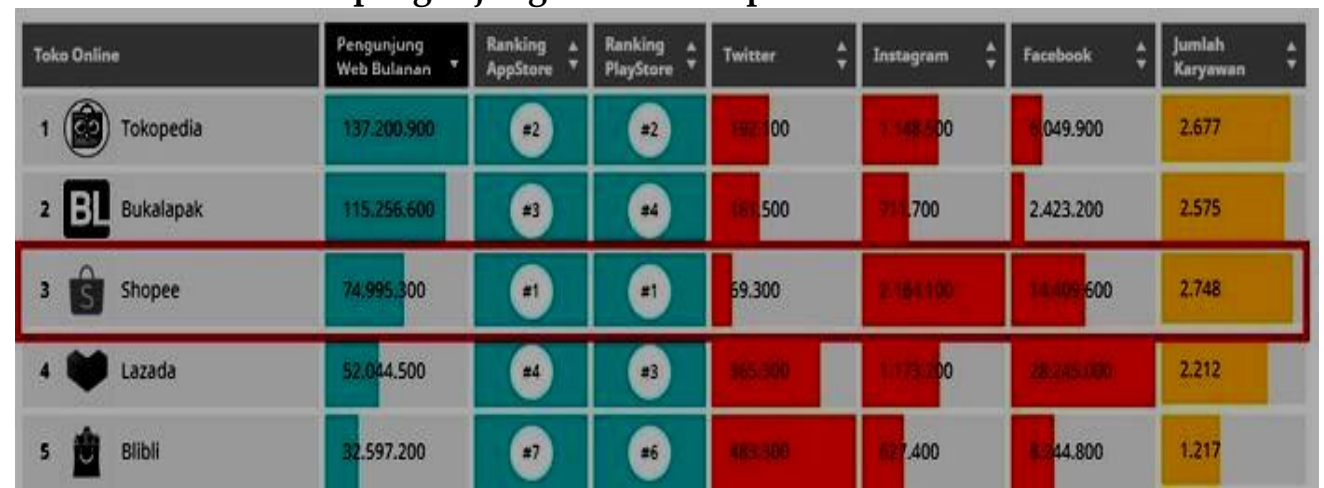

Sumber: Nextren, 2019

Akan tetapi pada kuartal kedua 2019 Shopee sukses menggusur Bukalapak diposisi kedua. Shopee mencatat pengunjung web sebanyak 90,7 juta setiap bulan, sementara Bukalapak hanya berbeda tipis 89,7 juta pengunjung per bulan. 
Tabel 2. Data pengunjung e-commerce pada kuartal ke 2 tahun 2019

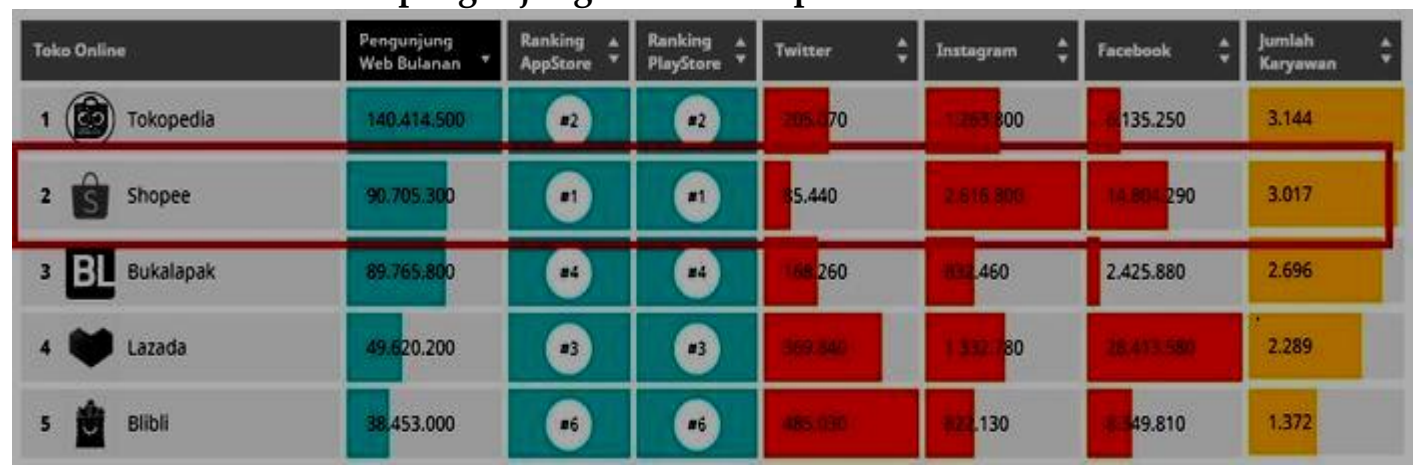

Sumber: Nextren, 2019

Berikut data mini riset terhadap Impulse buying yang dilakukan pada pengguna E-commerce Shopee di Kabupaten Kebumen kepada 34 reponden.

Tabel 3. Data mini riset

\begin{tabular}{lcc}
\hline \multicolumn{1}{c}{ Variabel } & $\begin{array}{c}\text { Jumlah } \\
\text { Responden }\end{array}$ & Persentase \\
\hline Sales Promotion & 23 & $67 \%$ \\
Hedonic Shopping Motivaton & 5 & $15 \%$ \\
Shopping Lifestyle & 6 & $18 \%$ \\
Total & 34 & $100 \%$ \\
\hline
\end{tabular}

Sumber: Mini riset, 2019

Menurut Mowen \& Minor (2002:10) berpendapat bahwa impulse buying merupakan kegiatan pembelian mendadak tanpa ada perencanaan terlebih dahulu pada saat memasuki toko. Sedangkan menurut Engel et al. (2008:386) mendefinisikan impulse buying adalah pembelian yang terjadi ketika konsumen mengalmi perasaan tiba-tiba, penuh kekuatan dorongan yang kuat untuk membeli suatu dengan segera. Menurut Kotler (2012) perilaku konsumen adalah mempelajari cara individu, kelompok dan organisasi memilih, membeli, memakai serta memanfaatkan barang, jasa, gagasan atau pengalaman dalam rangka memuaskan kebutuhan dan hasrat mereka.

Di era modern saat ini, Impulse buying atau yang bisa disebut dengan pembelian tak terencana di E-commerce merupakan perilaku konsumen yang menarik bagi perusahaan online saat ini. Impulse buying merupakan perilaku dimana orang tersebut tidak merencanakan sesuatu dalam belanja. Menurut Utami (2014:50) pembelian tidak terencana merupakan suatu tindakan yang dibuat tanpa perencanaan sebelumnya, atau keputusan pembelian terjadi saat berada dalam suatu toko atau online shop. Pembelian tidak terencana ini adanya stimulus atau rangsangan yang terjadi saat berada dalam sebuah toko atau saat sedang melihat online shop. Menurut Rook \& Fisher (1995), mereka mendefinisikan impulse buying sebagai kecenderungan konsumen untuk membeli secara spontan, reflek, tiba-tiba dan otomatis. Impulse buying bisa terjadi dimana saja.

Pembeli yang melakukan Impulse buying jika terdapat adanya promosi atau penawaran khusus saat membuka aplikasi Shopee, Menurut Belch \& Belch (2015), Sales promotion atau promosi penjualan adalah aktivitas pemasaran yang menyediakan nilai tambah atau insentif kepada tenaga penjual (sales force), distributor atau pelanggan utama dengan tujuan utama yaitu dapat menstimuli penjualan secara cepat. Kotler \& Armstrong (2012) mengemukakan pengertian promosi adalah promotion means activities that communicate the merits of the product and persuade 
targe customers to buy it. Artinya promosi merupakan kegiatan yang mengkomunikasikan manfaat dari sebuah produk dan membujuk target konsumen untuk membeli produk tersebut.

Menurut Swastha \& Irawan (2005) promosi atau persuasi satu arah dibuat untuk mengarahkan seseorang atau organisasi kepada tindakan yang menciptakan pertukaran dalam pemasar. Promosi dilakukan dengan mengkombinasi beberapa elemen promosi yang dikenal dengan promotion mix. Di dalam promosi, ada 5 hal penting yang menarik konsumen untuk melakukan impulse buying yaitu advertising, personal selling, publicity, sales promotion dan direct marketing.

Untuk memenangkan persaingan antar e-commerce, Shopee melakukan aktivitas komunikasi pemasaran yang mendorong pembelian seketika (impulsive buying). Menurut Utami (2014:50) pembelian tidak terencana merupakan suaru tindahan yang dibuat tanpa perencanaan sebelumnya, atau keputusan pembelian terjadi saaat berada dalam toko atau online shop. Salah satu strategi stimulus yang membentuk pembelian seketika adalah Sales Promotion. Bentuk sales promotion yang dilakukan untuk meningkatkan penjualan diantaranya adalah diskon harga, hadiah gratis, gratis ongkos kirim dan banded atau penjualan bersama-sama (bundling).

Faktor lain yang mempengaruhi Impulse buying adalah adanya Hedonic Shopping Motivation merupakan aktivitas untuk membeli sesuatu. Kegiatan berbelanja meliputi dua aktivitas, yaitu aktivitas memperoleh informasi tentang ketersediaan pilihan, karakteristik detail transaksi disebuah toko online dan aktivitas memperoleh barang dan jasa. Motivasi berbelanja diperkirakan menjadi salah satu penyebab dari keberagaman hasil tersebut. Menurut Utami (2014:47) seseorang akan senang berbelanja karena orang tersebut merasa mendapatkan kesenangan panca indera, mimpi dan mempertimbangkan estensis. Menurut Utami (2014:49) Ada 6 faktor motivasi belanja hedonis, antara lain: Adventure shopping, social shopping, gratification shopping, idea shopping, role shoping dan value shopping.

Konsumen berbelanja karena termotivasi oleh keinginan hedonis atau alasan ekonomi, seperti kesenangan, fantasi dan sosial atau kepuasan emosional. Sejak tujuan pengalaman berbelanja untuk mencukupi kebutuhan hedonis, produk yang dibeli ini kelihatan seperti terpilih tanpa perencanaan dan akan menghadirkan suatu impulse buying. Impulse buying diawali ketika konsumen melakukan kegiatan pencarian informasi/browsing. Konsumen yang suka belanja, memiliki kecenderungan lebih besar untuk mencari informasi tentang produk tertentu. Dari informasi yang diperoleh, akan tercipta keinginan untuk memiliki produk tersebut sehingga akan memutuskan melakukan kegiatan pembelian. Konsumen yang berbelanja dengan motif hedonis, ketika melakukan pencarian informasi dapat merasakan kesenangan dalam memeriksa unsur-unsur visual pada toko online.

Banyaknya produk-produk yang disediakan oleh Shopee maka itu akan membuat konsumen selalu ingin mengikuti perkembangan zaman. Maka dari itu akan timbul suatu gaya hidup yang akan berpengaruh terhadap keinginan dan kebutuhan konsumen. Menurut Edwin dan Sugiono (2011), "Shopping lifestyle adalah pola konsumsi yang mencerminkan pilihan seseorang tentang bagaimana cara menghabiskan waktu". Seseorang yang sudah mengikuti perkembangan gaya hidup seperti dengan fashion, rela menghabiskan waktu untuk mengikuti trend terbaru.

Dari Identifikasi Masalah Diatas Dalam Mengetahui Besar Pengaruh Sales Promotion, Hedonic Shopping Motivation Dan Shopping Lifestyle Terhadap Impulse Buying maka hipotesis yang dibangun pada penelitian ini adalah sebagai berikut :

$\mathbf{H}_{1}$ : Terdapat pengaruh Sales Promotion terhadap Impulse buying

$\mathbf{H}_{2}$ : Terdapat pengaruh Hedonic Shopping Motivation terhadap impulse buying 
$\mathbf{H}_{3}$ : Terdapat pengaruh Shopping Lifestyle terhadap Impulse buying

$\mathbf{H}_{4}$ : Terdapat pengaruh secara simultan Sales Promotion, Hedonic Shopping Motivation dan Shopping Lifestyle terhadap Impulse buying

\section{Kajian Teori dan Telaah Literatur}

Menurut Utami (2010:67) Pembelian impulsif atau pembelian tidak terencana merupakan bentuk lain dari pola pembelian konsumen. Sesuai dengan istilahnya, pembelian tersebut tidak secara spesifik terencana. "pembelian impulsif" terjadi ketika konsumen tiba-tiba mengalami keinginan yang kuat dan kukuh untuk membeli sesuatu secepatnya.

Gutierrez (2004:1061) bahwa pembelian tidak direncanakan pada dasarnya adalah pembelian yang terjadi seketika. Biasanya konsumen dengan tipe pembelian ini pernah mengalami kekecewaan dengan pembelian produk sebelumnya sehingga cenderung berhati-hati dalam melakukan pembelian. Pada penelitian ini impulse buying dibatasi oleh 4 indikator: pembelian secara spontan, pembelian dilakukan secara terburu-buru, pembelian dipengaruhi oleh emosi, pembelian dilakukan tanpa memikirkan akibat.

Menurut Belch \& Belch (2015: 529) dalam Felita \& Oktivera (2019:165), Sales promotion atau promosi penjualan adalah aktivitas pemasaran yang menyediakan nilai tambah atau insentif kepada tenaga penjual (sales force), distributor atau pelanggan utama dengan tujuan utama yaitu dapat menstimuli penjualan secara cepat. Dari definisi-definisi tersebut dapat disimpulkan bahwa sales promotion adalah alat-alat insentif yang dipakai untuk merangsang pembelian atau penjualan suatu produk atau jasa secara cepat dan lebih besar yang biasanya bersifat jangka pendek, Berikut merupakan alat promosi penjualan menurut Kotler dan Keller (2012:543) yang sesuai dengan E-commerce Shopee : kupon, harga khusus, premi, penghargaan dukungan, garansi produk, Price-off.

Menurut Arnold \& Reynolds (2003) motivasi hedonis merupakan suatu kegiatan pembelian yang didorong dengan perilaku yang berhubungan dengan panca indera, khayalan dan emosi yang menjadikan kesenangan dan kenikmatan materi sebagai tujuan utama hidup. Kebanyakan orang pasti memiliki sifat bahagia dan senang kalau sudah berbelanja baik itu secara langsung maupun tidak langsung.

Menurut Utami dalam Widia $(2019,277)$," seseorang akan senang berbelanja karena orang tersebut merasa mendapatkan kesenangan dan merasa bahwa belanja itu adalah sesuatu hal yang menarik. Jadi, motivasi ini didasarkan pada pemikiran yang subjektif atau emosional karena mencangkup respon emosional, kesenangan panca indra, mimpi dan pertimbangan estensis. Kategori motivasi belanja hedonis melalui internet menurut To et al. (2007:777), yaitu: petualangan, sosial, ide, nilai,. kekuasaan dan status.

Gaya hidup (Shopping Lifestyle) menurut Kotler (2008) adalah pola hidup seseorang di Dunia yang diexpresikan dalam aktivitas, minat dan opininya. Gaya hidup menggambarkan keseluruhan diri sseorang dalam berinteraksi dengan lingkunganya, gaya hidup menggambarkan seluruh pola seseorang dalam beraksi dan berinteraksi di dunia.

Gaya hidup berbelanja juga berkaitan erat dengan berkembangnya jaman dan teknologi yang emakin maju. Menurut Edwin dan Sugiono (2011), "Shopping lifestyle adalah pola konsumsi yang mencerminkan pilihan seseorang tentang bagaimana cara menghabiskan waktu". Seseorang yang sudah mengikuti perkembangan gaya hidup seperti dengan fashion, rela menghabiskan waktu untuk mengikuti trend terbaru. maka bisa dirinci indikator dari shopping lifestyle, sebagai berikut: berbelanja merupakan kegiatan rutin untuk memenuhi semua 
kebutuhan, berbelanja merupakan kegiatan sosial untuk bisa berhubungan dengan orang lain, berbelanja dengan memilih tempat berbelanja menunjukkan status sosial konsumen, terdapat perencanaan secara periodik untuk berbelanja

\section{Metode Penelitian}

Variable bebas dalam penelitian ini terdiri dari 3 variabel yaitu Sales Promotion, Hedonic Shopping Motivation dan Shopping Lifestyle dasatu variabel terikatnya adalah impulse buying. Populasi dari penelitian ini adalah seluruh masyarakat Kebumen yang pernah menggunakan e-commerce Shopee sebagai tempat pembelian. Teknik sampel yang digunakan adalah non probability sampling dimana teknik pengambilan sampel yang tidak memberi peluang/kesempatan sama bagi setiap unsur atau anggota populasi untuk dipilih menjadi sampel. Menurut Umar (2000:150) karena di dalam penelitian ini jumlah populasi tidak diketahui, maka penentuan jumlah sampel dalam penelitian ini di ambil dengan menggunakan rumus slovin. Berdasarkan perhitungan rumus didapat 96 responden dan untuk memudahkan perhitungan digenapkan menjadi 100 responden.

Pemberian skor pada kuisioner menggunakan 5 point Skala Likert yang bermakna: $1=$ sangat tidak setuju, 2 = tidak setuju, $3=$ netral, $4=$ setuju, dan $5=$ sangat setuju. Teknik analisis data yang digunakan dalam penelitian ini terdiri dari uji instrumen validitas dan reliabilitas, uji asumsi klasik (uji normalitas, uji heterokesdastisitas, dan uji multikolinieritas), analisis regresi berganda (Uji t dan Uji F), dan koefisien determinasi.

\section{Hasil dan Pembahasan}

Hasil uji instrumen validitas dan reliabilitas menunjukkan bahwa semua item pengukuran dalam kuisioner dinyatakan valid dan reliabel. Hal ini didasarkan pada hasil uji validitas $r$ hitung untuk semua item pengukuran variabel $>r_{\text {tabel }}=0,198$ dengan tingkat signifikansi $<$ 0,05, sedangkan hasil uji instrumen reliabilitas menunjukkan bahwa nilai Alpha Cronbach dari keempat variabel $>0,6$.

Hasil uji asumsi normalitas menunjukkan bahwa data berdistribusi normal. Hal ini didasarkan pada gambar plot normalitas pada gambar dibawah ini yang menunjukkan bahwa data menyebar di sekitar/mendekati dan mengikuti garis diagonal.

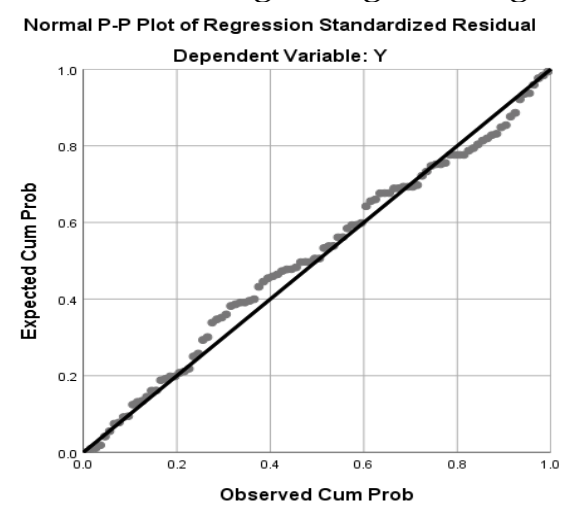

Gambar 2. Hasil uji normalitas

Sumber : Data Primer diolah, 2020

Hasil uji heterokesdastisitas menunjukkan bahwa data bebas heterokesdastisitas. Hal ini didasarkan pada hasil scatterplot dibawah ini dengan bulatan-bulatan kecil yang tidak 
memiliki suatu pola tertentu yang teratur (bergelombang, melebar, kemudian menyempit) dan tidak terdapat pola yang jelas, sehingga disimpulkan tidak terdapat gejala heterokesdastisitas

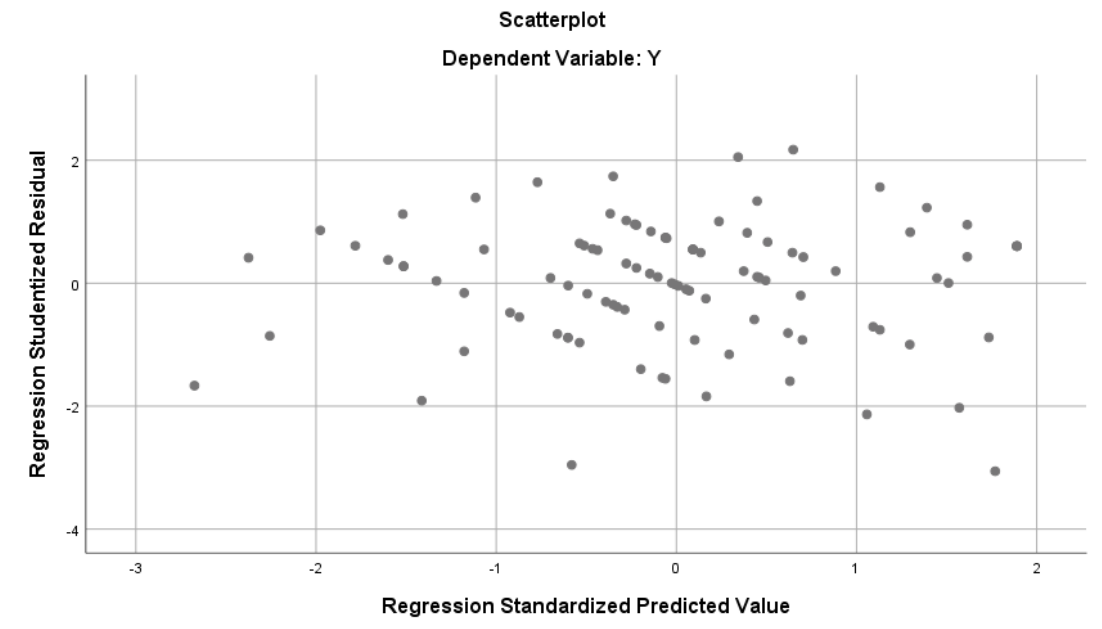

Gambar 3. Hasil uji heterokedastisitas

Sumber : Data Primer diolah, 2020

Hasil uji multikolinieritas menunjukkan bahwa data bebas gejala multikolinieritas. Hal ini didasarkan pada hasil Collinearity Statistics di bawah ini yang menunjukkan bahwa nilai Tolerance semua variabel berada di atas 0,10 (10\%) dan nilai VIF semua variabel berada di bawah 10. Berdasarkan hasil uji normalitas, heterokesdastisitas, dan multikolinieritas maka dapat dikatakan bahwa tidak terdapat masalah asumsi klasik pada penelitian ini.

\begin{tabular}{cc}
\multicolumn{2}{c}{ Tabel 4. Hasil uji multikolinieritas } \\
Collinearity Statistics \\
Tolerance & VIF \\
\hline .513 & 1.950 \\
.352 & 2.844 \\
.447 & 2.237 \\
\hline
\end{tabular}

Uji t merupakan satu pengujian individu terhadap variabel independent $(\mathrm{X})$ dimana untuk mengetahui pengaruh yang signifikan terhadap variabel dependent $(\mathrm{Y})$, yaitu variabel Sales Promotion $\left(\mathrm{X}_{1}\right)$, Hedonic Shopping Motivation $\left(\mathrm{X}_{2}\right)$ dan Shopping Lifestyle $\left(\mathrm{X}_{3}\right)$ terhadap Impulse Buying $(Y)$. Dalam pengujian ini ditentukan tingkat signifikan sebesar $5 \%(\alpha=0,05)$ dengan tingkat keyakinan sebesar $95 \%(0,95)$. Untuk mengetahui hasil analisis $t$ dalam penelitian ini dapat dilihat sebagai berikut: 


\begin{tabular}{ccccc}
\hline Variabel & Signifikan & $\mathbf{\alpha}$ & $\begin{array}{c}\mathbf{t} \\
\text { hitung }\end{array}$ & $\mathbf{t}_{\text {tabel }}$ \\
\hline $\mathrm{X}_{1}$ & 0.000 & 0,05 & 3,696 & 1,984 \\
$\mathrm{X}_{2}$ & 0.002 & 0,05 & 3,176 & 1,984 \\
$\mathrm{X}_{3}$ & 0.039 & 0,05 & 2,094 & 1,984
\end{tabular}

Sumber : Data Primer diolah, 2020

Pembahasan Hipotesis 1: Sales Promotion mempunyai pengaruh yang signifikan terhadap impulse buying di e-commerce Shopee. Berdasarkan hasil analisis diketahui bahwa variabel Sales Promotion $\left(X_{1}\right)$ mempunyai nilai $t_{\text {hitung }}$ sebesar 3,696 $>t_{\text {tabel }} 1,984$ dengan tingkat signifikan 0,000 $<0,05$. Kondisi ini menunjukkan bahwa variabel Sales Promotion memiliki pengaruh yang positif dan signifikan terhadap impulse buying di e-commerce Shopee. Hal ini sama dengan hasil penelitian yang dilakukan oleh Patricia Felita (2019) bahwa sales promotion shopee Indonesia berpengaruh signifikan terhadap impulse buying pada mahasiswa STIKS Tarakanita.

Pembahasan Hipotesis 2: Hedonic Shopping Motivation mempunyai pengaruh yang signifikan terhadap impulse buying di e-commerce Shopee. Berdasarkan hasil analisis bahwa variabel Hedonic Shopping Mtivation $\left(\mathrm{X}_{2}\right)$ mempunyai nilai $t_{\text {hitung }}$ sebesar 3,176 $>t_{\text {tabel }}$ 1,984 dengan tingkat signifikan 0,002< 0,050. Kondisi ini menunjukkan bahwa Hedonic Shopping Motivation memiliki pengaruh yang positif dan signifikan terhadap impulse buying di e-commerce Shopee. Hal ini sama dengan hasil penelitian yang dilakukan Widia Sefiska Rahma dan Whyosi Septrizola (2019) bahwa Hedonic Shopping Motivation berpengaruh terhadap impulse buying pada mahasiswa Universitas Negeri Padang pada Lazada.co,id.

Pembahasan Hipotesis 3: Shopping Lifestyle mempunyai pengaruh yang signifikan terhadap impulse buying di e-commerce Shopee. Sesuai dengan analisis bahwa variabel Hedonic Shopping Motivies $\left(X_{3}\right)$ mempunyai nilai $t_{\text {hitung }}$ sebesar 2,094 $>t_{\text {tabel }} 1,984$ dengan tingkat signifikan 0,039 $<0,05$. Kondisi ini menunjukkan bahwa Shopping Lifestyle memiliki pengaruh yang positif dan signifikan terhadap impulse buying di e-commerce Shopee. Hal ini sama dengan hasil penelitian yang dilakukan oleh Lia Octaria Pasaribu dan Citra Kusuma Dewi (2015) bahwa Hedonic Shopping Motivation berpengaruh terhadap impulse buying pada Toko online Zalora.

Uji $\mathrm{F}$ digunakan untuk mengetahui apakah terdapat hubungan yang nyata antara variabel independent $(\mathrm{X})$ dengan variabel dependent $(\mathrm{Y})$ secara bersama-sama. Hasil Uji $\mathrm{F}$ yang telah dilakukan dengan menggunakan SPSS 25.0 diperoleh hasil sebagai berikut: 
Tabel 6. Hasil analisis uji $F$

\begin{tabular}{|c|c|c|c|c|c|c|}
\hline \multicolumn{7}{|c|}{ ANOVA $^{a}$} \\
\hline & Model & Sum of Squares & $\mathrm{df}$ & $\begin{array}{l}\text { Mean } \\
\text { Square }\end{array}$ & $\mathrm{F}$ & Sig. \\
\hline 1 & Regression & 299.394 & 3 & 99.798 & 48.919 & $.000^{\mathrm{b}}$ \\
\hline & Residual & 195.846 & 96 & 2.040 & & \\
\hline & Total & 495.240 & 99 & & & \\
\hline
\end{tabular}

a. Dependent Variable: $Y$

b. Predictors: (Constant), X3, X1, X2

Sumber : Data Primer diolah, 2020

Pembahasan Hipotesis 4 : Berdasarkan hasil uji ANOVA, diperoleh nilai $\mathrm{F}$ hitung sebesar 48,919 dengan tingkat signifikan 0,000 < 0,05 dan $\mathrm{F}$ hitung sebesar 48,919 lebih besar dari $\mathrm{F}$ tabel 2,70 maka dapat disimpulkan bahwa secara bersama-sama Sales promotion, hedonic shopping motivation dan shopping lifestyle mempunyai pengaruh signifikan terhadap Impulse Buying di ecommerce Shopee pada masyarakat Kabupaten Kebumen.

Koefisien determinasi digunakan untuk mengukur besarnya kontribusi variabel independent dengan variabel dependent sehingga dapat diketahui variabel yang paling mempengaruhi variabel dependent.

Tabel 7. Hasil analisis interprestasi koefisien determinasi $\left(\mathbf{R}^{2}\right)$

\begin{tabular}{c|c|c|c|c} 
Model & $\mathrm{R}$ & $\begin{array}{c}\mathrm{R} \\
\text { Squa } \\
\text { re }\end{array}$ & $\begin{array}{c}\text { Adjusted } \\
\text { R Square }\end{array}$ & $\begin{array}{c}\text { Std. Error of } \\
\text { the Estimate }\end{array}$ \\
\hline 1 & $.778^{\mathrm{a}}$ & .605 & .592 & 1.428 \\
\hline
\end{tabular}

Sumber : Data Primer diolah, 2020

Secara keseluruhan penelitian ini menunjukkan bahwa koefisien determinasi (Adjusted R2) sebesar 0,605. Hal ini bermakna bahwa variabel impulse buying (dependent) yang dapat dijelaskan oleh variabel sales promotion, hedonic shopping motives dan shopping lifestyle (independent) dalam penelitian ini sebesar 60,5\% sedangkan sebesar 39.5\% dipengaruhi oleh variabel lain yang tidak dijelaskan oleh penelitian ini

\section{Penutup dan Saran}

Berdasarkan hasil dan pembahasan maka penelitian ini dapat disimpulkan sebagai berikut: 1.) Sales Promotion berpengaruh poistif dan signifikan terhadap impulse buying di e-commerce Shopee. Hasil tersebut menunjukkan bahwa semakin tinggi Sales Promotion maka semakin meningkatkan impulse buying di e-commerce Shopee, 2.) Hedonic Shopping Motivation berpengaruh positif dan signifikan terhadap impulse buying di e-commerce Shopee. Hasil tersebut menunjukkan bahwa semakin tinggi Hedonic Shopping Motivation maka semakin meningkatkan impulse buying di e-commerce Shopee, 3.) Shopping Lifestyle berpengaruh positif dan signifikan terhadap impulse buying di e-commerce Shopee. Hasil tersebut menunjukkan bahwa semakin tinggi Shopping Lifestyle maka semakin meningkatkan impulse buying di ecommerce Shopee. 
Berdasarkan hasil penelitian saran dalam penelitian ini adalah sebagai berikut: 1.) Sales promotion dapat mempengaruhi impulse buying pada konsumen. Konsumen lebih meilih produk yang dijual dengan kualitas yang sama tetapi terdapat promosi penjualan daripada produk dengan banderol harga normal, 2.) Perilaku hedonic shopping motivation juga mempengaruhi impulse buying. Konsumen dengan motivasi senang belanja yang tinggi tentunya memiliki pengaruh belanja tidak terencana pastinya lebih tinggi dibanding konsumen yang belanjanya tidak memiliki motivasi senang berbelanja, 3.) Adanya Shopping lifestyle pada konsumen bisa mempengaruhi impulse buying. Konsumen selalu ingin tahu dan mengikuti trend. 4.) Sesuai dengan hasil uji koefisien determinasi $\left(\mathrm{R}^{2}\right)$ diperoleh 0,605 sehingga variabel impulse buying (dependent) yang dapat dijelaskan oleh variabel sales promotion, hedonic shopping motives dan shopping lifestyle (independent) dalam penelitian ini sebesar 60,5\% sedangkan sebesar 39.5\% dipengaruhi oleh variabel lain yang tidak dijelaskan oleh penelitian ini. Sehingga dapat disimpulkan bahwa model ini mempunyai kemampuan yang cukup besar dalam menjelaskan variabel dependent. Hasil ini dapat digunakan untuk memperkaya referensi dan ilmu pengetahuan berkaitan dengan impulse buying pada e-commerce perusahaan Shopee atau perusahan e-commerce lainnya untuk penelitian penelitian-penelitian yang akan datang yang lebih mendalam

\section{Referensi}

Arnold, M. J., \& Reynolds, K. E. (2003). Hedonic shopping motivations. Journal of retailing, 79(2), 77-95.

Belch, G. E., \& Belch, M. A. (2003). Advertising and promotion: An integrated marketing communications perspective. New York: The McGraw- Hill.

Databoks .2019. Indonesia Jadi Negara dengan Pertumbuhan E-Commerce Tercepat di Dunia. Di download dari :

Felita, P., \& Oktivera, E. (2019). PENGARUH SALES PROMOTION SHOPEE INDONESIA TERHADAP IMPULSE BUYING KONSUMEN Studi Kasus: Impulse Buying pada mahasiswa STIKS Tarakanita. Jurnal Ilmu Komunikasi dan Bisnis, 4(2), 159-185.

Gutierrez, B. P. B. (2004). Determinants of planned and impulse buying: the case of the Philippines. Asia Pacific Management Review, 9(6), 1061-1078.

https:// databoks.katadata.co.id/datapublish/2019/04/25/indonesia-jadi-negaradengan-pertumbuhan-e-commerce-tercepat-di-dunia. Diakses pada tanggal 20 September 2019.

Husein, U. (2000). Riset Pemasaran Dan Penilaian Konsumen. Jakarta: PT Gramedia Pustaka.

Japarianto, E., \& Sugiharto, S. (2011). Pengaruh Shopping Lifestyle dan Fashion Involvement Terhadap Impulse Buying Behavior Masyarakat High Income Surabaya, 6 (1), 124. Retrieved from Jurnal Management Pemasaran.

Kotler, P. (2008). Manajemen Pemasaran, Edisi Milenium diterjemahkan Benyamin Molan, PT. Prenhallindo, Jakarta.

Kotler, P. (2012). Manajemen Pemasaran, alih bahasa Bob Sabran. Jakarta: Erlangga.

Kotler, P., \& Amstrong, G. (2007). Prinsip-Prinsip Pemasaran. Edisi 13. Jilid 1. Jakarta: Erlangga. 
Mowen, J. C., \& Minor, M. (2002). Perilaku konsumen. Jakarta: Erlangga.

Nextren. (2018). Inilah Tren E-commerce 2018 di Indonesia. Tersedia di http://nextren.grid.id/read/0124363/inilah-tren-e-commerce-2018-di-indonesiamenurut-toko-daring-ini?page=all. diakses pada 19 september 2019

Nextren. (2019). Catatan E-Commerce Indonesia Kuartal 2 2019: Shopee Salip BukaLapak. Tersedia di https://nextren.grid.id/read/011857132/catatan-e-commerce-indonesiakuartal-2-2019-shopee-salip-bukalapak?page=all. diakses pada 19 september 2019

Rook, D. W., \& Fisher, R. J. (1995). Normative influences on impulsive buying behavior. Journal of consumer research, 22(3), 305-313.

Sugiyono. (2012). Metode Penelitian Kuantitatif Kualitatif dan RED. Bandung: CV. Alfabeta.

Swasta, B., \& Irawan (2005). Asas-asas marketing. Yogyakarta: Liberty.

To, P. L., Liao, C., \& Lin, T. H. (2007). Shopping motivations on Internet: A study based on utilitarian and hedonic value. Technovation, 27(12), 774-787.

Utami, C. W. (2010). Manajemen Ritel (edisi 2). Jakarta: Salemba Empat.

Utami, C. W. (2014). Strategi Dan Implementasi Oprasional Bisnis Ritel Modern Di Indonesia. Jakarta: Salemba Empat. 